\title{
FINISHING BURNING EFFECT PADA PENCIPTAAN PATUNG KERAMIK UNTUK MENGHADAPI KOMPETISI MASYARAKAT EKONOMI ASEAN (MEA)
}

\author{
Lutse Lambert Daniel Morin dan Otok Herum Marwoto *)
}

\begin{abstract}
ABSTRAK
Penelitian ini adalah sebuah eksplorasi penciptaan untuk mendapatkan produk keramik yang menekankan pada effect finishing guna terciptanya keramik yang memiliki nuansa etnis Indonesia sehingga dapat berkompetisi pada pasar global. Hal ini bertujuan untuk meningkatkan daya saing produk-produk para pengrajin keramik dalam rangka menghadapi pasar bebas asia tenggara atau sering disebut Masyarakat Ekonomi Asean (MEA). Target penelitian pada tahun pertama menciptakan produk keramik dengan finishing burning untuk memperoleh efek yang unik dan menarik. Teknik burning terhadap unsur cat baik yang water base maupun oil base dapat memberikan kesan antik dan maskulin sesuai dengan kecenderungan desain (trend desain) saat ini. Metode yang dilakukan adalah dengan melakukan eksperimen pada proses finishing keramik guci untuk menghasilkan efek bakar.
\end{abstract}

Kata Kunci: keramik, finishing burning effect, masyarakat ekonomi Asean.

\section{PENDAHULUAN}

Pembentukan Masyarakat Ekonomi ASEAN (MEA) bagi Indonesia tentu saja akan memberikan kesempatan yang baik untuk menaikkan ekspor karena hambatan perdagangan sudah tidak ada. Tetapi pada sisi yang lain, dampak yang akan muncul dari MEA adalah semakin tingginya tekanan persaingan, terutama dengan negaranegara lain yang produktifitas serta infrastrukturnya telah memadai seperti Singapura dan Malaysia. Belum lagi, selama ini produk Cina begitu banyak membanjiri pasar Indonesia, sebaliknya produk-produk ekspor Indonesia masih sangat kurang, sehingga defisit neraca perdagangan masih sering terjadi.
Salah satu produk yang selama ini menjadi andalan ekspor Daerah Istimewa Yogyakarta untuk Negara-negara Eropa, Australia, dan Amerika adalah produkproduk kerajinan keramik, terutama dari sentra kerajinan Kasongan, Bantul. Kesempatan produk-produk keramik para usaha mikro kecil menegah (UMKM) kerajinan untuk masuk ke MEA sangat besar, hal ini ditandai dengan mulai banyaknya para buyer yang datang dari Thailand, Singapore, dan Malaysia.

Penelitian ini sebagai salah satu bagian dari usaha untuk mencari, meneliti serta menciptakan produk-produk kerajinan keramik yang dapat bersaing, terutama menghadapi persaingan pasar

*) Lutse Lambert Daniel Morin, Staf Pengajar Program studi Seni Rupa Murni, Fakultas Seni Rupa, Institut Seni Indonesia Yogyakarta. Otok Herum Marwoto (otok_hm@gmail.com), Staf Pengajar Program studi Kriya Seni, Jurusan Kriya, Fakultas Seni Rupa, Institut Seni Indonesia Yogyakarta. 
bebas Asean. Penelitian ini akan mewujudkan keramik-keramik baru terutama dari sisi finishing dalam bentuk prototype, kemudian dipromosikan oleh UMKM dalam sebuah pameran perdagangan internasional seperti IFFINA/IFEK maupun Trade Expo Indonesia di Jakarta sehingga dapat menjaring para buyers internasional, yaitu para mengimpor produk seni kerajinan dari Indonesia ke negaranya. Dengan demikian diharapkan akan terjadi interaksi dalam menawarkan desain baru itu sebagai upaya uji pasar dan kemungkinan pemesanannya.

Ada dua permasalahan yang diteliti yaitu bagaimanakah menciptakan produk seni kerajinan keramik berbasis finishing burning effect yang dapat diterima pada pasar Asean dan bagaimanakah desain, proses perwujudan, prototype, uji pasar, dan reproduksi produk baru seni kerajinan keramik.

Tujuan penelitian ini adalah untuk menghasilkan bentuk dan karakter seni kerajinan keramik khas Indonesia baru, kreatif, inovatif yang sesuai dengan ciri, sifat, bentuk, dan karakter yang berkembang di pasar internasional. Memperkaya desain baru yang lebih bervariatif. Produk seni kerajinan keramik memang saat ini mengalami penurunan akibat krisis global, sehingga produk baru dan variatif akan menjadi pilihan bagi para pembeli. Meningkatkan nilai ekonomis seni kerajinan keramik untuk dapat diterima di pasar eksport, sehingga ekonomi masyarakat pengrajin seni kerajinan keramik memperoleh peningkatan penghasilan.

Adapun manfaaat penelitian ini adalah menjadi acuan para pengrajin keramik sehingga dapat mengembangkan usahanya menjadi usaha ekonomi kreatif yang berkelanjutan. Menciptakan produk patung keramik dengan desain dan teknik yang baru sehingga memperkaya bentuk dan jenis-jenis patung keramik yang diproduksi pengusaha lokal. Penciptaan produk patung keramik baru sebagai hasil pengorganisasian seni akan memberikan nuansa pembeda baik dari karakter, effect, bentuk, dan teknik produksinya. Hasil survei memperlihatkan bahwa desain baru seni kerajinan selalu mengalami penjiplakan dari produsen lain baik di Asia Tenggara maupun di Cina dan India, maka hasil penelitian ini sangat perlu diusulkan agar memperoleh hak cipta HKI sebagai karya yang mencerminkan karakter Indonesia. Meningkatkan produk seni patung keramik sebagai salah satu komoditi ekspor sehingga dapat meningkatkan pendapatan domestic bruto (PDB).

\section{Metode}

Dalam penelitian ini adalah untuk menghasilkan seni kerajinan keramik baru berbasis finishing burning, maka dalam penelitian ini menggunakan frame estetis dan ekonomis. Estetis adalah proses eksplorasi mencari bentuk dan finishing yang unik dan kreatif, dan ekonomis adalah kemampuan produk itu dalam memberikan dampak ekonomi pada masyarakat pengrajin. Adapun alur prosesnya sebagai berikut,

\section{Studi Pustaka dan Observasi}

Studi pustaka dan observasi untuk pengumpulan data dan informasi yang diperlukan sesuai dengan masalah penelitian, yakni masalah desain baru yang sesuai dengan pasar MEA dan 
potensi ketrampilan membuat gerabah dan finishing burning agar sesuai dengan minat konsumen.

\section{Perwujudan}

Melalui eksplorasi dan eksperimentasi diterjemahkan dalam sketsa alternatif, eksperimen bentuk, penentuan bentuk, dan finishing produk. Tahapan dari proses pembentukan persiapan bahan, persiapan alat, finishing burning effect. Selama proses perwujudan prototype dilakukan pengamatan dan pencatatan sehingga dapat menghasilkan produk seni kerajinan keramik yang sesuai dengan minat konsumen.

\section{Uji kelayakan pasar}

Uji coba pengukuran pasar ini menjadi teknik riset baik untuk mengurangi resiko yang ada pada produk baru dan menilai keberhasilannya dengan mengukur ketertarikan mereka. Metode yang digunakan dalam uji coba pasar adalah menggunakan uji coba pasar dimana penerimaan calon pembeli bisa diamati dan dianalisis lebih dekat.

Analisis yang digunakan adalah analisis diskriptif kualitatif, sementara untuk mengetahui jumlah dan nominal peningkatan penjualan produk baru dalam skala pasar akan disinggung juga analisis kuantitatif. Seluruh data yang diperoleh akan dianalisis disajikan secara naratif dan data yang berupa hasil penelitian akan disajikan dalam bentuk gambar.

\section{Eksplorasi Burning Efeck pada patung keramik}

Kata keramik berasal dari Bahasa Yunani "keramos" yang berarti periuk atau belanga yang dibuat dari tanah. Sedangkan gerabah berasal dari Bahasa Jawa yang berarti segala produk yang dibuat oleh manusia dari bahan tanah liat, melalui proses pembakaran. Seni keramik merupakan seni kerajinan yang menggunakan bahan baku tanah liat melalui proses pembentukan mulai dari dipijit, butsir, pilin, hingga proses pembakaran dan juga glasir. Wujud atau hasil seni keramik bermacam-macam seperti guci, patung loro blonyo, alat rumah tangga dan lain sebagainya.

Burning effect merupakan salah satu teknik pewarnaan yang menggunakan bantuan api untuk membakar dan mengeluarkan warna pada benda yang ingin diwarnai. Teknik ini biasa diterapkan pada besi dan batu.

Beberapa jenis patung keramik pernah dbuat dan dikembangkan sebagai produk lokal oleh para pengrajin keramik. Patung keramik tersebut ada yang berukuran kecil dan sedang. Bentuk-bentuk patung yang ada mulai dari bentuk binatang dan bentuk hewan. Berikut beberapa bentuk patung yang ada di pasaran dan diproduksi oleh pengrajin yang ada di Yogyakarta berdasarkan survey yang dilakukan.

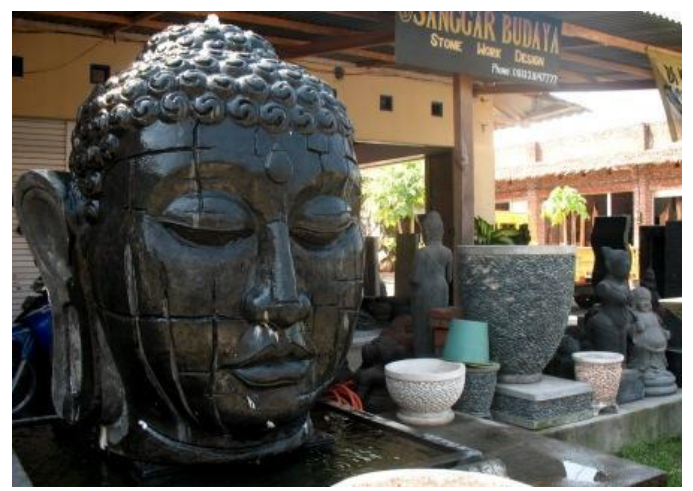

Gambar 1. Patung keramik yang dicat hitam di Desa Kasongan Bantul Yogyakarta 


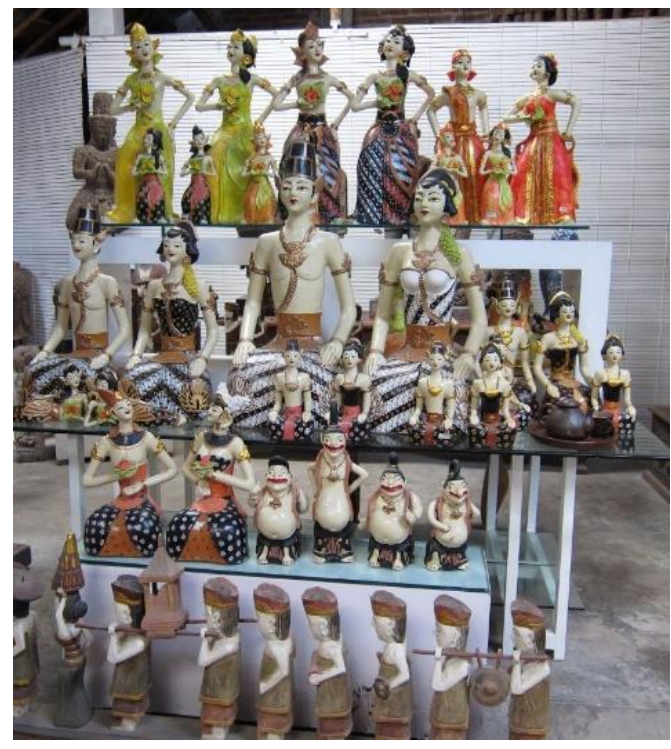

Gambar 2. Patung keramik yang dicat dengan tema pewayangan di Desa Kasongan Bantul Yogyakarta

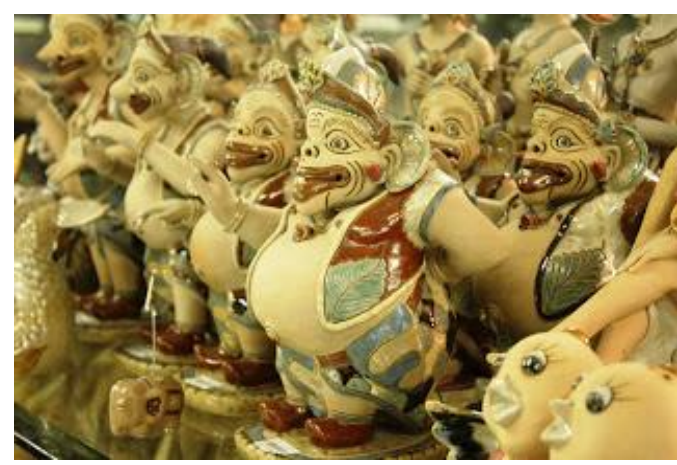

Gambar 3. Patung keramik yang dijual dikawasan Malioboro Yogyakarta

Berdasarkan survey yagn dilakukan penulis, ada beberapa tempat yang biasa menggunakan teknik burning effect pada karya seni. Berikut beberapa foto burning effect yang dilakuan oleh pengrajin maupun seniman.

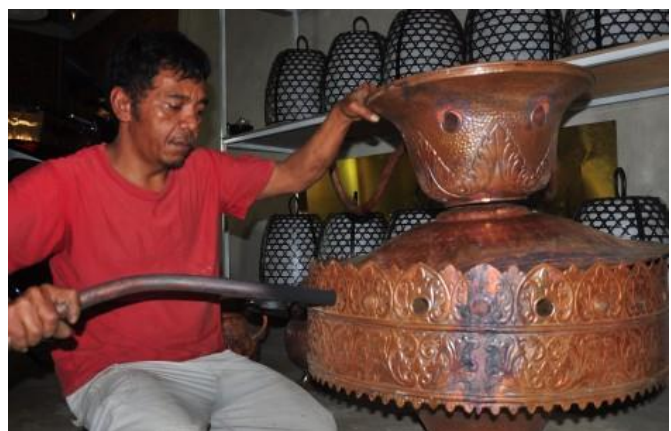

Gambar 4. Warna tembaga dengan teknik bakar pada logam tembaga di Desa Tumang Boyolali Jawa Tengah

\section{Desain Patung}

Mendesain berarti merancang atau rancangan. Setelah melalui beberapa tahapan survey, maka dibuatlah beberapa desain atau rancangan sebagai luaran penelitian ini. Beberapa desain dipilih dan diwujudkan dalam bentuk patung. Berikut beberapa desai yang akan diwujudkan kedalam seni tiga dimensi.

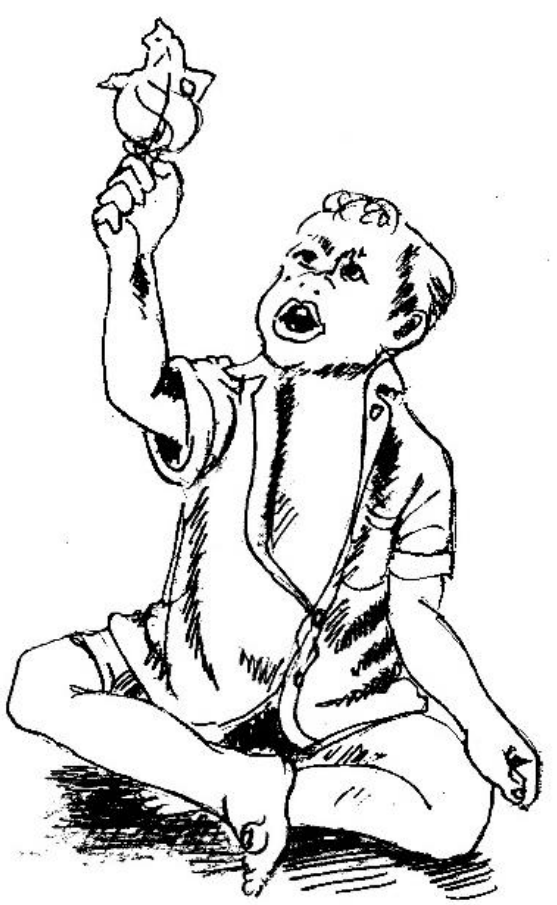




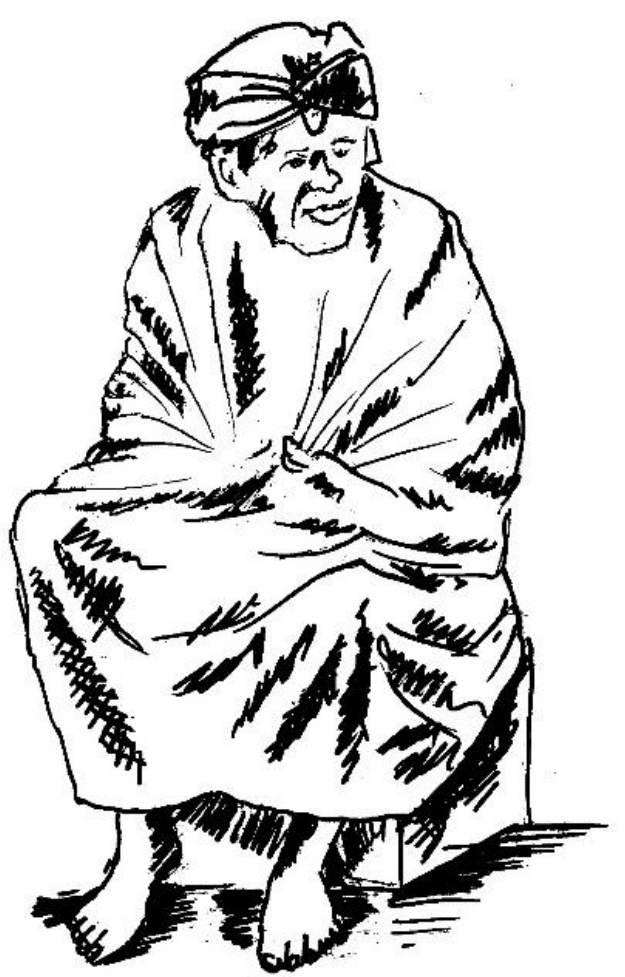

Gambar 6. Sket 2

\section{Prototype}

Prototype merupakan sebuah bentuk dan ukuran yang digunakan sebagai acuan dalam pembuatan patung selanjutnya. Prototype dibuat berdasarkan gambaran atau desain yang telah dibuat. Prototype inilah yang akan dibuat cetakan dan digandakan. Berikut beberapa prototype yang ditelah dibuat dan dijadikan acuan.

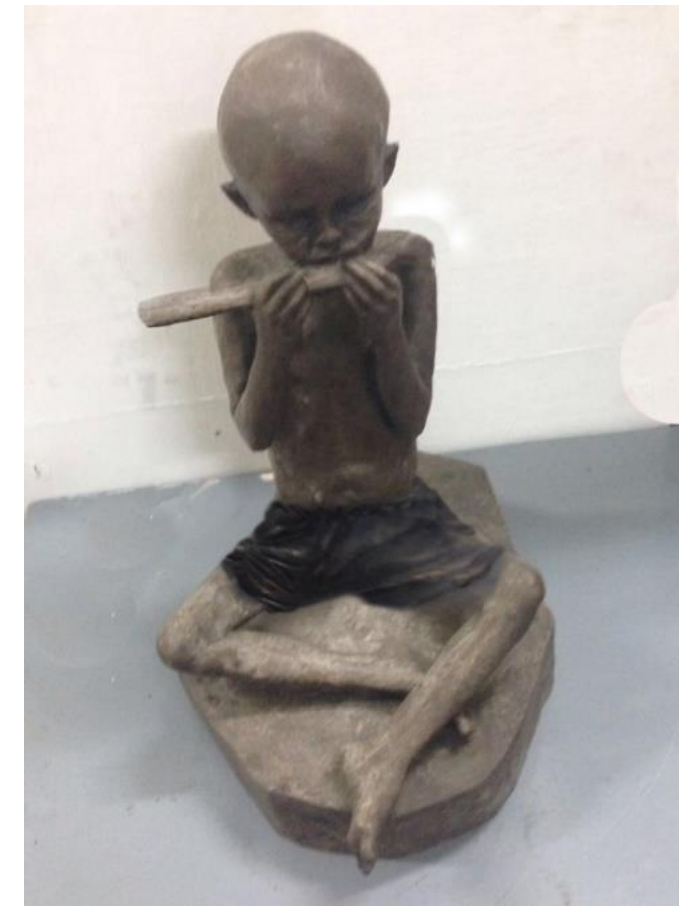

Gambar 7. Prototype 1

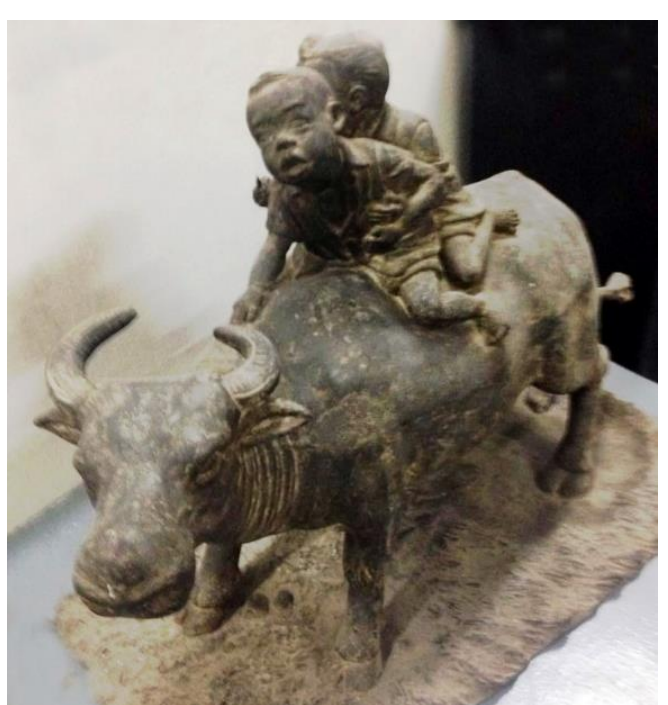

Gambar 8. Prototype 2 


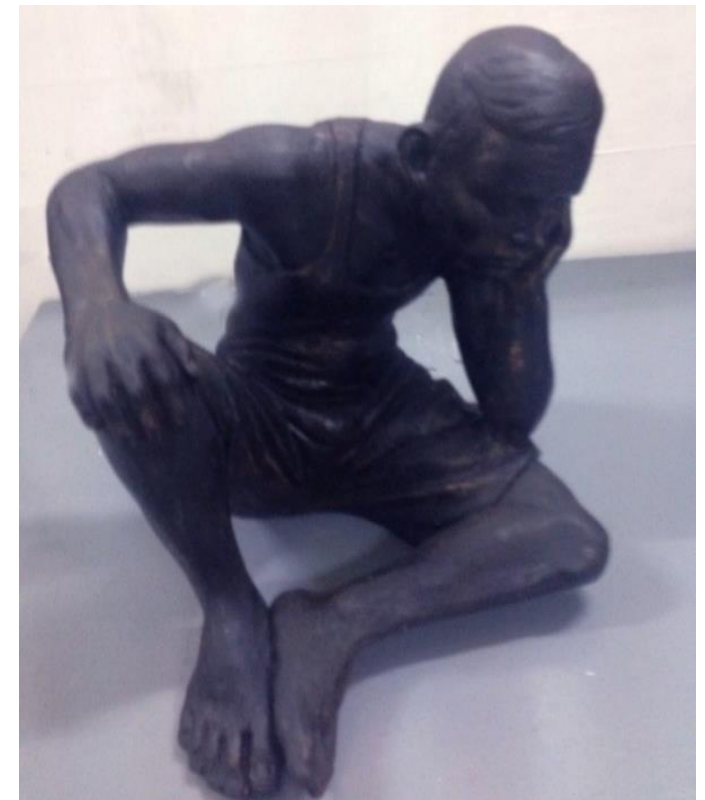

Gambar 9. Prototype 1

\section{Proses Pembuatan Patung Keramik}

Patung keramik yang ada saat ini memiliki bentuk yang dekoratif. Sehingga terkadang orang bosan melihatnya. Patung tiga dimensi biasa dibuat oleh seniman merupakan bentuk tiga dimensi yang realis sehigga tidak bosan orang melihat dan bentuknya ledih detail serta menarik. Berdasarkan hal tersebuat maka terciptalah desain patung manusia dengan bentuk realis yang mengangkat seni tradisional. Seperti yang kita tahu, sesuatu yang tradisional akan selalu menjadi hal menarik bagi bagi masyarakat internasional.

Desain-desain yng telah dibuat dan dipilih selanjutnya akan dieksekusi kedalam bentuk riel. Proses awal pembuatan patung ini adalah membauta master patung. Master patung dibuat melalui proses modelling dengan bahan tanah liat. Tanah liat tersebut dibuat dan dibentuk sedemikian rupa sehingga realis menyerupai bentuk asli manusia dengan berbagai bentuk yang mengangkat seni tradisi.

Setelah modelling jadi, tahap berikutnya adalah membuat cetakan patung berdasarkan model patung tersebut. Bahan yang digunakan adalah fiber glass atau polyester resin. Pengecoran cetakan ini dibagi menjadi beberapa bagian. Hal ini bertujuan untuk memudahkan ketika cetakan dicor dan menjadi patung master. Sebelum di olesi resin, terlebih dahulu model patung diberi pemisah agar nantinya setelah cetakan mengeras dapat dipisahkan dari master patung yang terbuat dari tanah liat. Model patung yang telah diolesi pemisah selanjutnya dapat diolesi campuran fiber selapis demi selapis sampai ketebalan yang dirasa cukup kuat. Setelah mengeras, cetakan dapat dibuka dan dibersihkan.

Tahap selanjutnya adalah pengecoran cetakan patung menggunakan bahan fiber. Hasil pengecoran ini berupa patung master yang nantinya dibuat cetakan keramik. Bahan yang digunakan untuk membuat cetakan keramik adalah silikon. Pemilihan bahan ini didasarkan pada sifat silikon ynag elastis sehingga ketika diisi tanah liat dan dikeluarkan dari cetakan, patung hasil cetakan tidak rusak. Cetakan silicon ini juga dibuat menjadi beberapa bagian yang disatukan dengan rumah cetakan terbuat dari fiber. Sekrup digunakan untuk mengencangkan rumah cetakan agar patung bisa menyatu dengan baik. 


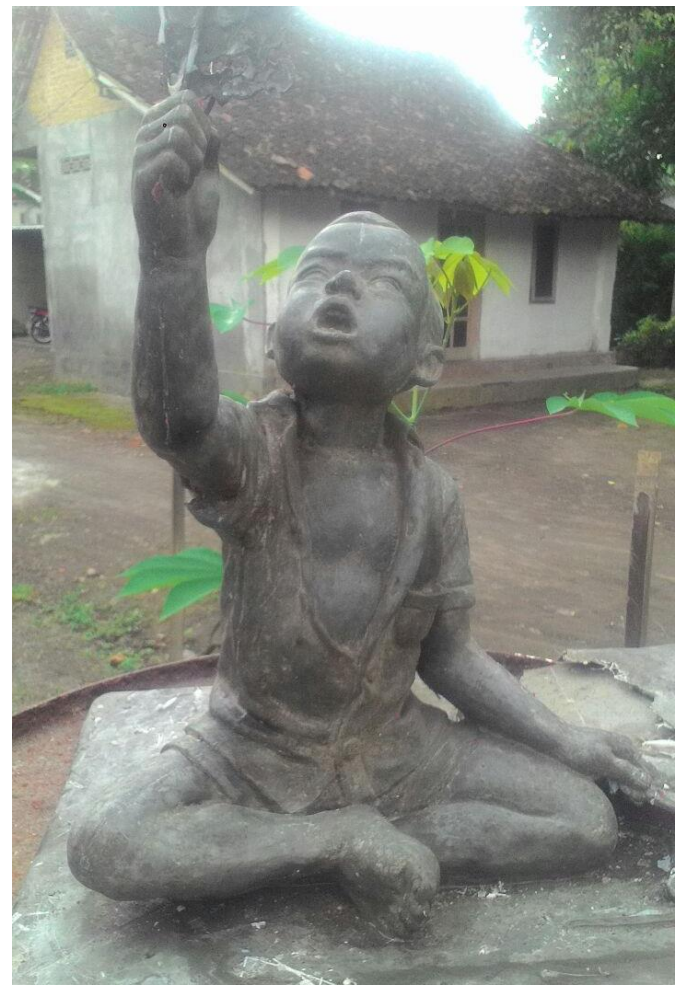

Gambar 10. Model master patung anak bermain wayang

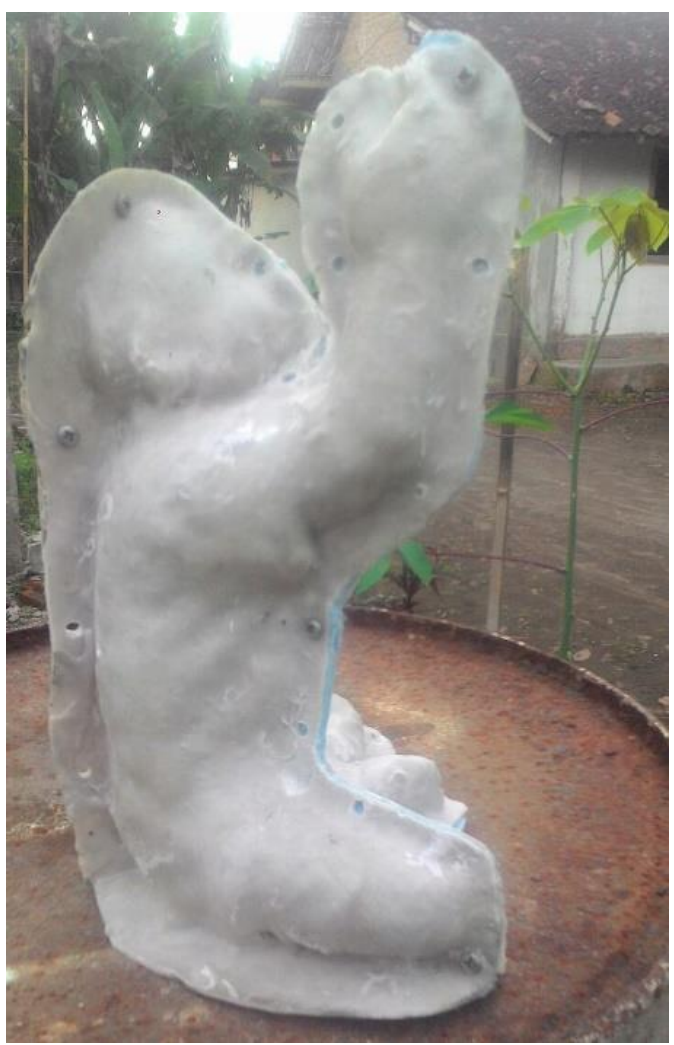

Gambar 11. Cetakan patung

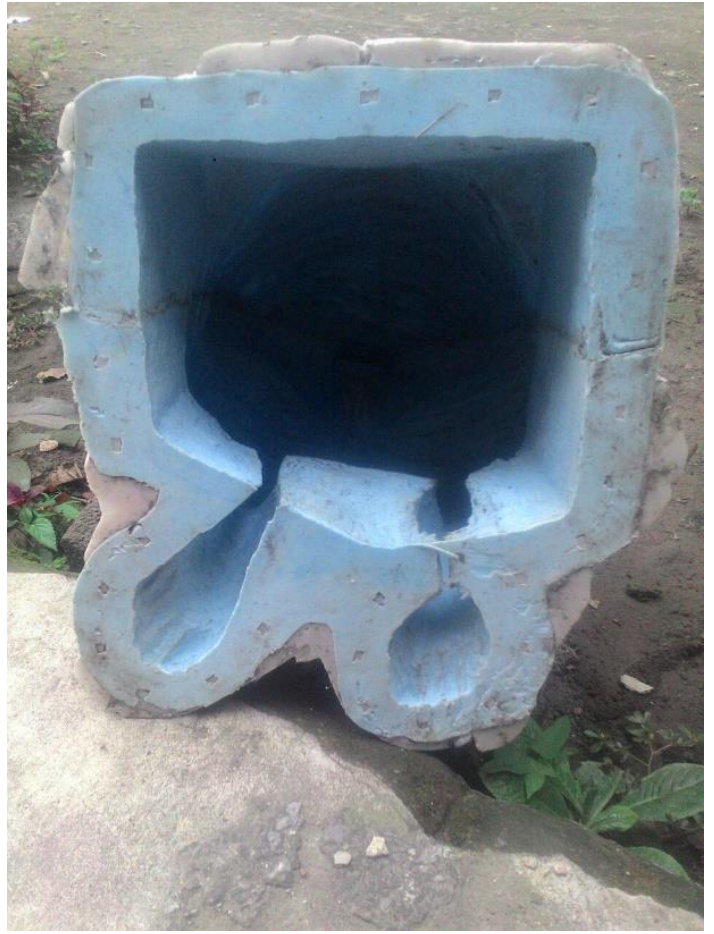

Gambar 12. Cetakan silikon siap untuk dituang keramik

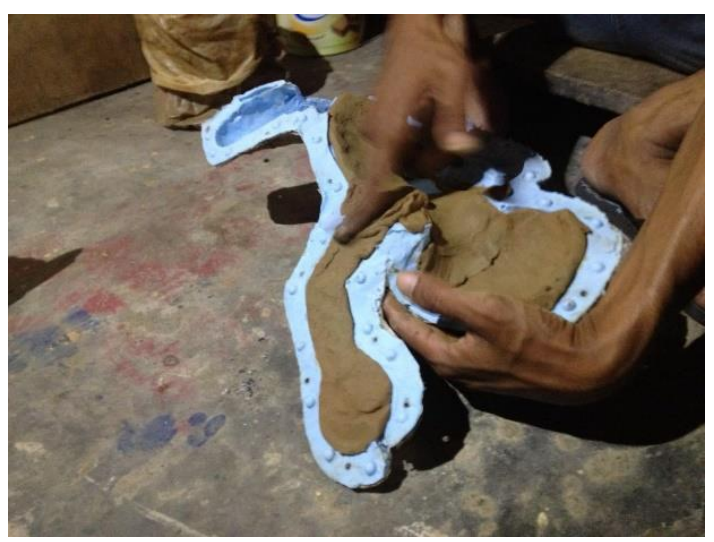

Gambar 13. Proses cetak keramik 1 


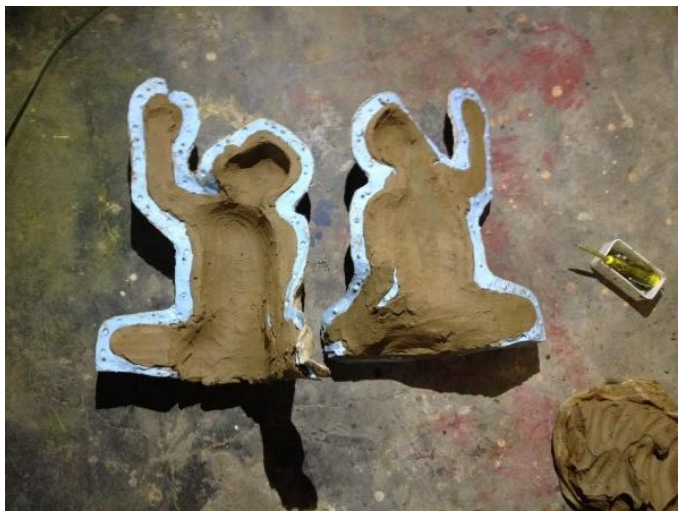

Gambar 14.Proses cetak keramik 2

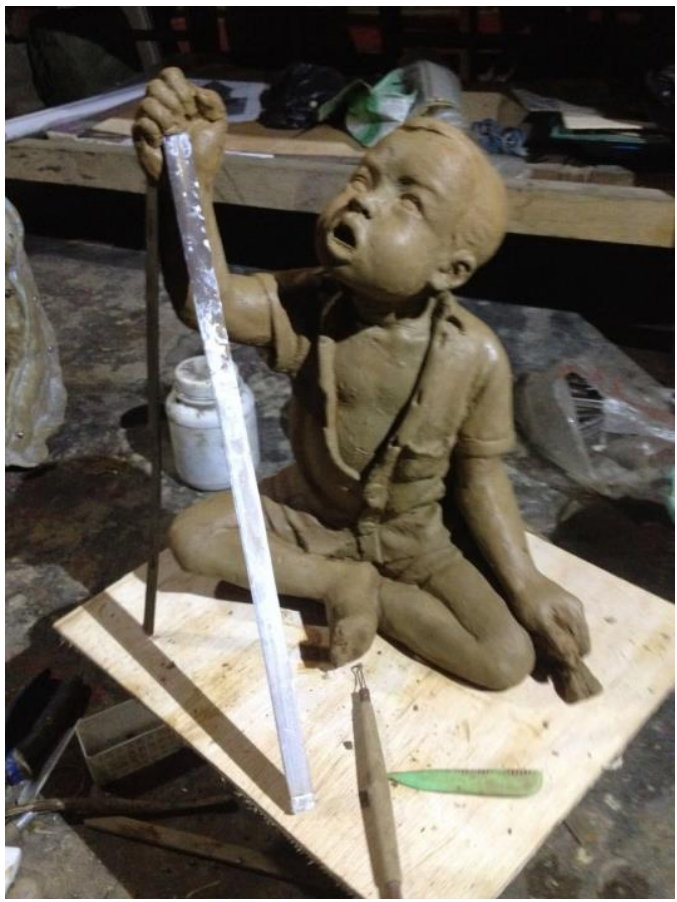

Gambar 15. Hasil cetakan keramik

\section{PEWARNAAN PATUNG}

a. Menggunakan bahan kimia: a) Bahan: hcl, kuningan, seng sari, air accu/air hujan; b) Alat: blower air, kuwas, kain, ember plastik, spray gun, mangkok plastik, penyaring ukuran 0,01 atau kain; c) Teknik pembuatan: $\mathrm{Hcl} 1$ liter dimasukkan ke dalam ember plastik dimasukkan serbuk kuningan/ lempengan kuningan/ batangan kuningan $2 \mathrm{~kg}$ ditambah dengan seng sari $0,5 \mathrm{~kg}$ dan didiamkan selama 3 hari. Lima jam pertama dari pencampuran, campuarn hcl tersebut diaduk. Pengadukan dilakukan setelah campuran tidak lagi mengeluarkan asap dan buih. Hari berikutnya campuran diaduk sampai endapan tercampur benar. Pada hari keempat cairan disaring dengan menggunakan saringan yg terbuat bukan dari logam. Hasil saringan ini kemudian dimasukkan ke dalam alat spray gun yang terbuat dari plastik. Setelah cairan siap, siapkan air acu, kuwas, dan blower api. Cairan kemudian disemprotkan pada keramik yang sudah melalui pembakaran dan dalam kondisi dingin secara merata sambil disemprot api. Pendinginan patung yang sudah disemprot dilakukan dengan mengguanakan kuwas yang sudah dibasahi dengan air acu. Caranya dengan dioleskan pada bagian-bagian patung. Patung kemudian ditunggu sampai air acunya meresap pada keramik. Prosesini diulang-ulang sampai warna yang sesuai yang diinginkan.

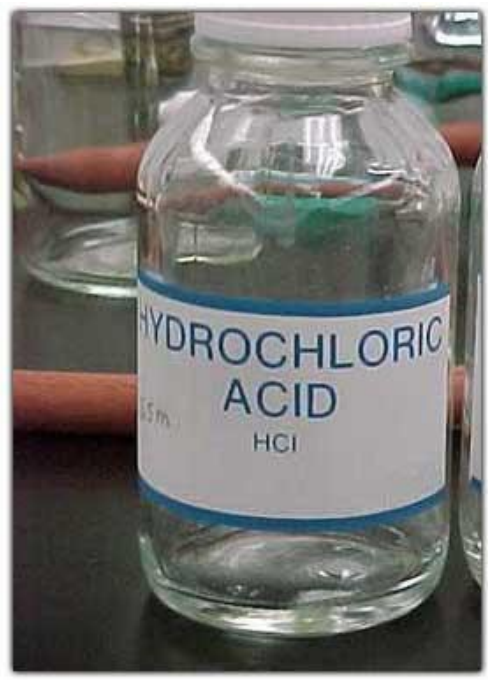




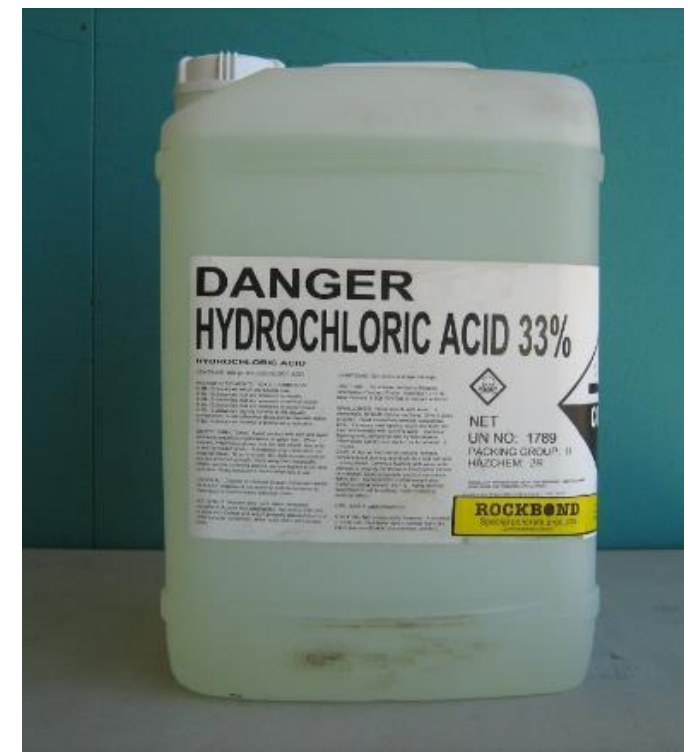

Gambar 16. HCL

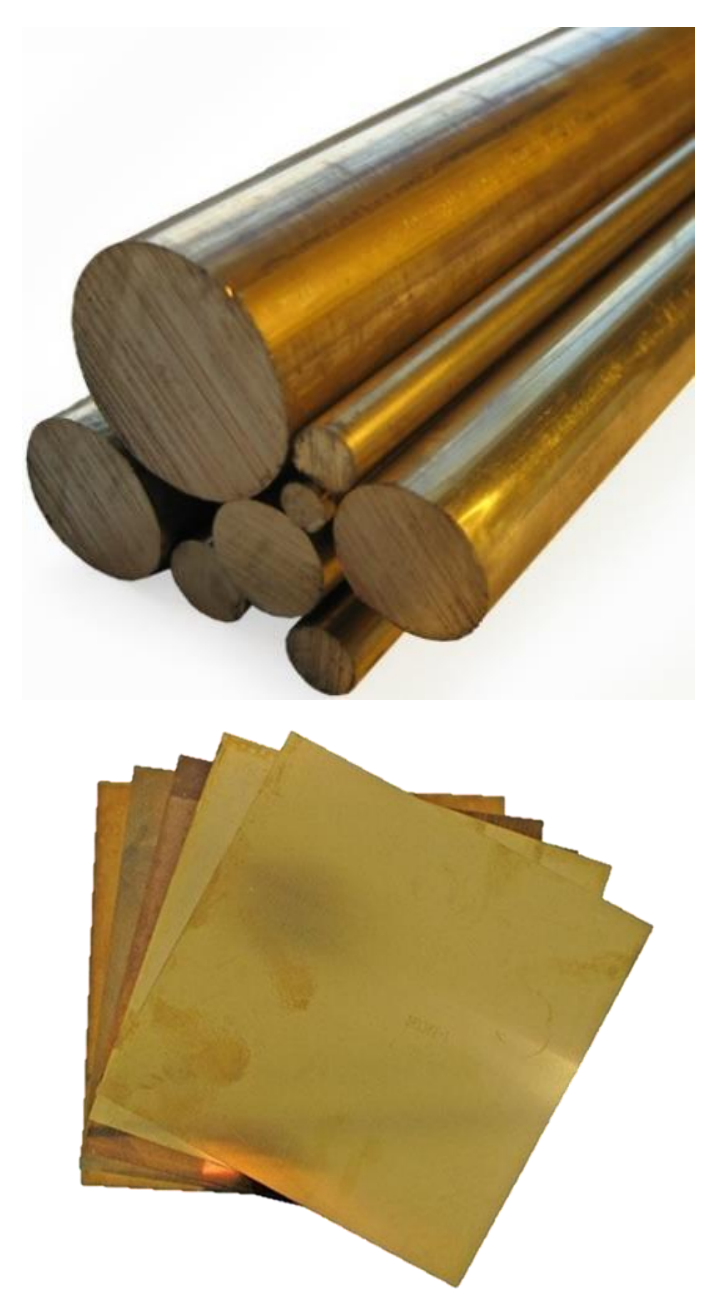

Gambar 17. Kuningan

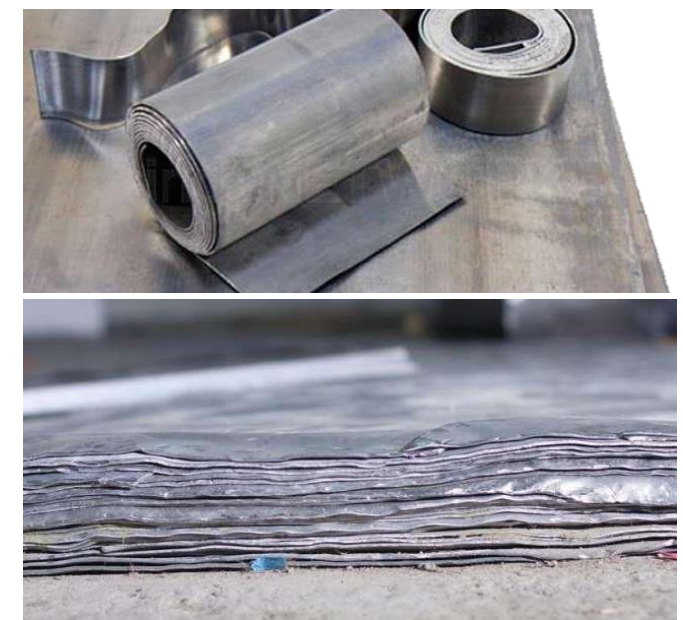

Gambar 18. Seng Sari
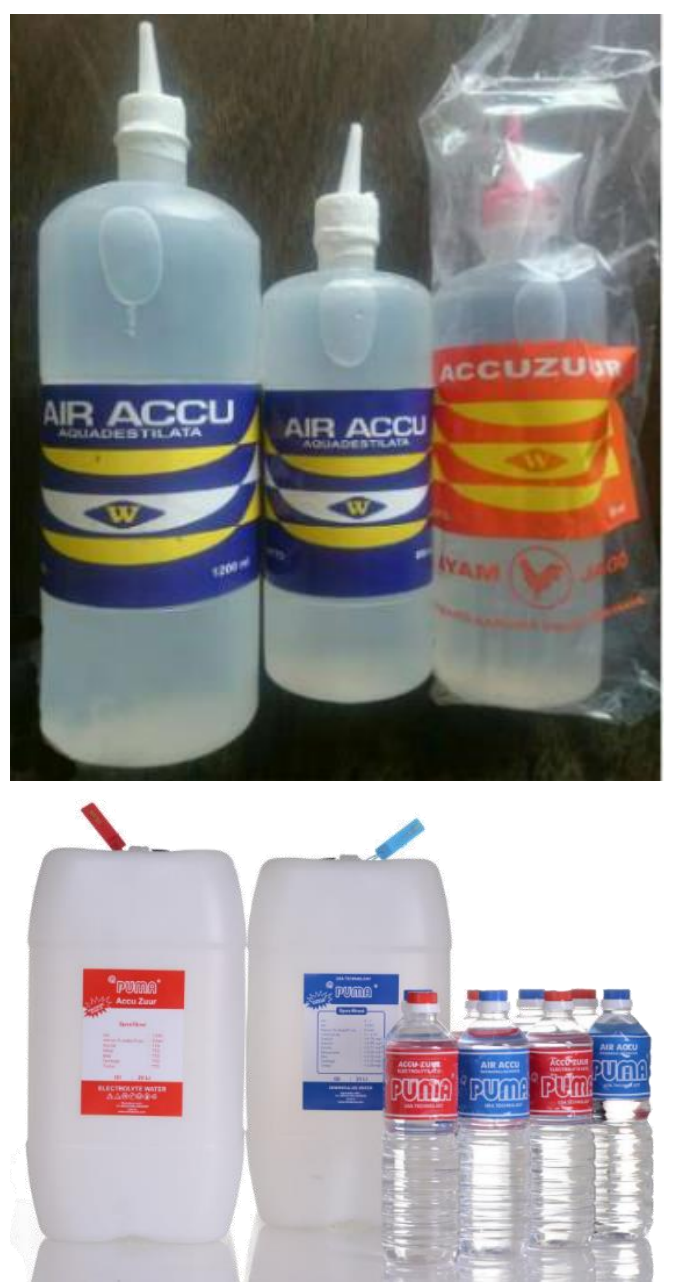

Gambar 19. Air Accu

b. Menggunkanan bahan alami: a) Bahan: teh/daun teh, kunyit, belerang, gambir, 
santan kelapa, getah pohon pisang, air; b) Alat: blower air, kuwas, kain, mangkok plastik, spray gun, penyaring ukuran 0,01 atau kain; c) Teknik pembuatan: pertama-tama teh diendapkan dalam air panas satu liter dalam ember plastik. Kunyit $1 / 4 \mathrm{~kg}$ yang ditumbuk halus ditambah gambir yang ditumbuk halus 1 ons, dan belerang $1 / 2$ ons kalau dalam bentuk kristal ditumbuk samapai halus. Semua bahan dicampur dalam keadaan air masih panas dan diaduk sampai tercampur rata lalu dinginkan. Langkah selanjutnya adalah penyaringan. Saringan yang digunakan adalah saringan halus/kain. Hasil saringan lalu dimasukkan ke dalam spray gun. Cairan ini kemudian di semprotkan ke permukaan patung keramik dan dihangatkan dengan blower api sambil dikuwas dengan santan kelapa yang dicampur dengan getah pisang sampai menimbulkan efek mengkilap. Proses ini diulangi sampai warna yang diinginkan dan permukaan mengkilat yang diharapkan. Terakhir patung digosok dengan kain yang bersih.

c. Menggunakan bahan dasar keramik: a) Bahan: tanah liat keramik, air,lem kayu; b) Alat: blower air, kuwas, kain kasa halus, mangkok plastic; c) Teknik pembuatan: tanah liat keramik $1 \mathrm{~kg}$ direndam dalam 5 liter air dan lem kayu $1 / 5 \mathrm{~kg}$ diaduk sampai seperti bubur cair dan disaring menggunakan saringan halus 0,05 atau menggunakan kain kasa alus kemudian diendapkan selama 6 jam lalu air yang jernih diatas endapan dibuang. Endapan kemudian dioleskan tipis pada patung keramik (tidak sampai menutup anatomi patung) sambil dihangatkan atau dibakar dengan blower api. Hasil yang ditampilkan adalah retak-retakan kecil pada patung. Proses ini diulang-ulang sampai sesuai dengan retakan yang diinginkan.

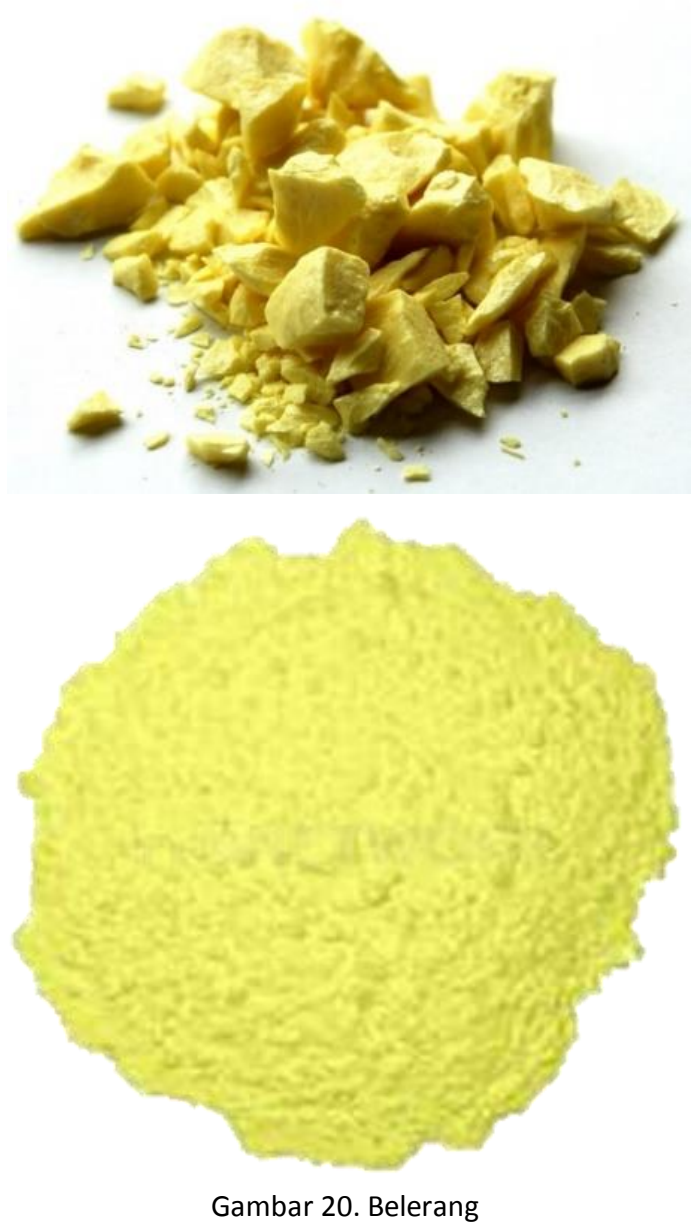



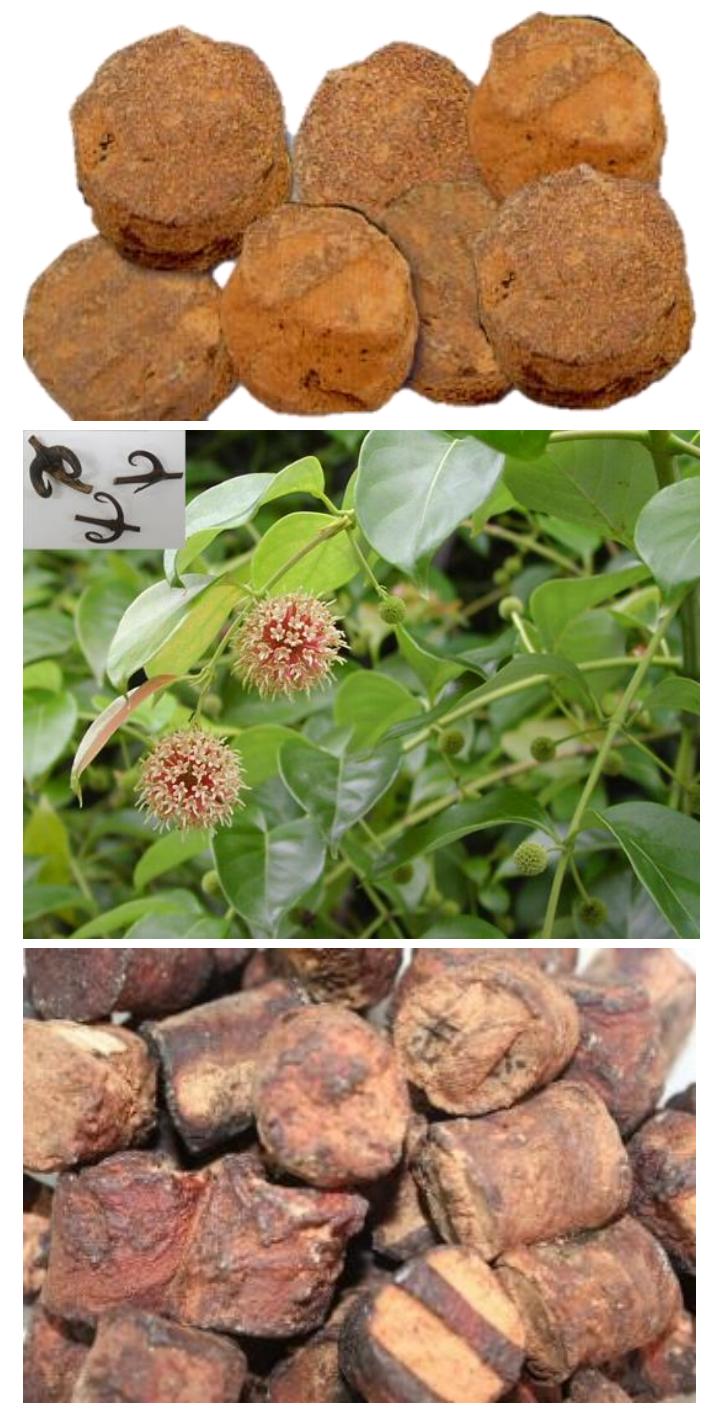

Gambar 21. Gambir

\section{PENUTUP}

Berdasarkan pembahasan di atas, dapat disimpulkan bahwa pewarnaan menggunakan bahan alami maupu kimia untuk logam, dapat diterapkan pada keramik menggunakan teknik burning effect. Proses pembutan patung keramik dimulai dari pembuatan modelling, pembuatan master, pembuatan cetakan keramik, mencetak keramik, pembakaran dan terakhir pewarnaan dengan cara dioleskan pewarna dan dibakar menggunakan api.

\section{DAFTAR PUSTAKA}

Akbar, Taufik, 2012, "Tanah Liat Talawi Sawah Lunto: Kajian Karakteristik dan Potensi Implementasi pada Karya Kriya Keramik", Skripsi, untuk menyelesaikan sarjana strata satu pada Jurusan Kriya ISI Yogyakarta.

Astuti, Ambar, 2008, Keramik IImu dan Proses Pembuatannya, Arindo Nusa Media, Jurusan Kriya Fakultas Seni Rupa ISI Yogyakarta.

Amir MS, 2005, Ekspor Impor Teori dan Penerapannya: Seri Bisnis Internasional No. 13, Penerbit PPM, Jakarta.

Domer, Peter, 1994, The New Ceramics Trend+Tradition, Thames and Hudson Ltd., London.

Guntur, 2000, "Keramik Kasongan dan Desain Baru", Tesis, Program Studi Seni Pertunjukan dan Seni Rupa Jurusan Ilmu Humaniora Program Pascasarjana Universitas Gadjah Mada, Yogyakarta.

Nizam, Akhmad, 2010, "Ethnic by Design Keramik kontemporer Panjangrejo", Penelitian LPM ISI Yogyakarta.

Razak R.A., 1992, Industri Keramik, Balai Pustaka, Media Wiata, Semarang. 
156 ] CORAK Jurnal Seni Kriya Vol. 5 No.2, Nopember 2016-April 2017

Raharjo, Timbul, 2001, Teko Dalam Perspektif Keramik, Tonil Press, Yogyakarta

Suharson, Arif, 2011, "Teknik Putar Tradisional Gerabah Proses dan Finishingnya", Arindo Offset, Yogyakarta

.................., "Finishing Bakar" materi ceramah, disampaikan pada para pengrajin Pulutan, Tondano, Sulawesi Utara, 2013.

Paak,Carl E., 1981, The Decorative Touch: Haow to Decorate, Glaze, and Fire Your Pots, Prentice-Hall, Inc., Englewood Cliffs, New Jersey, 07632.

Yuliarni, 2010, "Seni Keajinan Keramik Jorong Galogandang Kecamatan Rambatan dan Jorong Galogandang Kanagarian Andaleh di Sumatra Barat", Tesis, Pengkajian Seni minat utama Kriya Keramik di Program Pascasarjan ISI Yogyakarta. 